\title{
Toxicity of anti-fouling biocides to Parorchis acanthus (Digenea: Philophthalmidae) cercarial encystment
}

\author{
N. J. Morley ${ }^{1, *}$, K. M. Y. Leung ${ }^{1,2}$, D. Morritt ${ }^{1}$, M. Crane $^{1}$ \\ ${ }^{1}$ School of Biological Sciences, Royal Holloway, University of London, Egham TW20 0EX, United Kingdom \\ ${ }^{2}$ Swire Institute of Marine Science and Department of Ecology and Biodiversity, The University of Hong Kong, Hong Kong SAR
}

\begin{abstract}
The toxicity of the anti-fouling biocides tributyltin (TBTO), copper, and Irgarol 1051 (irgarol) at nominal concentrations ranging from 10 to $10000 \mathrm{\mu g}^{-1}$ was investigated against the speed of encystment and successful formation of a protective cyst of the cercariae of Parorchis acanthus. For all biocide exposures, cercariae had a much slower rate of encystment and reduced cyst formation than controls. Exposure of the snail host Nucella lapillus for $7 \mathrm{~d}$ caused complete cessation of cercarial shedding in irgarol-exposed snails but had no effect on cercarial encystment from TBTO and copper-exposed snails. The mechanisms of toxicity of the biocides are briefly discussed.
\end{abstract}

KEY WORDS: Parorchis · Nucella · Cercariae · Encystment - Tributyltin · Copper · Irgarol 1051

Resale or republication not permitted without written consent of the publisher

\section{INTRODUCTION}

Active biocides in anti-fouling paints have been used on boat hulls and aquaculture cages to control biological growth of target organisms for several years. This is because excessive fouling of ships results in increased frictional resistance, leading to loss of speed and decreased fuel efficiency (Hall et al. 1999). Historically copper, in various forms, had been used for controlling fouling (Evans 1981), but this was superseded by the more effective and longer-lasting tributyltin (TBT) as an active biocide until the early 1980s, when tributyltin was found to be highly toxic to non-target organisms. When regulatory restrictions on tributyltin use were introduced in the mid-1980s, Irgarol 1051 (irgarol) was promoted as an alternative biocide with reduced toxicity to aquatic life.

Concern regarding the toxicity of anti-fouling biocides, especially tributyltin, to non-target organisms has resulted in a number of studies to investigate associated pathology. In particular, the dogwhelk Nucella lapillus has been found to suffer extensively from imposex under the influence of tributyltin exposure. Imposex, whereby male characteristics become superimposed on the female genital system, causes sterility and female mortality in dogwhelks, leading to popula- tion declines in areas of high boating activity (Bryan et al. 1986). Recently the possibility of an association between the occurrence of imposex and the degree of infectivity of dogwhelks with the digenean Parorchis acanthus has been investigated with populations of $N$. lapillus within the UK (Evans et al. 2000). Although no relationship between parasite infectivity and the severity of imposex was apparent, the direct toxicity of antifouling biocides to $P$. acanthus has never been investigated, even though up to $65 \%$ of the host dogwhelk population can be infected (Evans et al. 2000).

Parorchis acanthus occurs throughout the coastal fringe of much of Europe and North America (Williams 1969). Although the larval stage occurs in Nucella lapillus, the adult lives in several bird species, especially gulls. Transmission to the bird host occurs when the cercarial stage is shed from the snail and encysts on surrounding substrate (e.g. mussel shells) which may form the diet of the target host. Previous toxicity studies with cadmium and zinc by Morley et al. (2001) have established that the parasite is most vulnerable during the short free-living and encysting stages of its life cycle. Once housed in its protective multi-layered cyst, the parasite is practically impervious to even acutely toxic concentrations of heavy metals. 
The specific objectives of this preliminary study were to elucidate the toxicity of the anti-fouling biocides tributyltin, copper, and irgarol to cercarial encystment of Parorchis acanthus by accelerated testing using acute concentrations not normally encountered in chronically polluted environments. The toxicity to the speed of encystment and the successful completion of a protective cyst were studied both directly on the cercariae themselves and on cercariae from biocide-exposed hosts.

\section{MATERIALS AND METHODS}

Stock solutions of tributyltin, copper and Irgarol 1051 were prepared by dissolving $1 \mathrm{~g}$ of either bis (tri-nbityltin) oxide (TBTO) (Acros Organics) or $\mathrm{N}^{\prime}$-Tert-Ncyclopropyl-6-(methylthio)-1,3,5-triazine-2-4-diamine (irgarol) (Ciba Speciality Chemicals) in $100 \mathrm{ml}$ of methanol, or by dissolving sufficient copper sulphate $\left(\mathrm{CuSO}_{4} \cdot 5 \mathrm{H}_{2} \mathrm{O}\right)$ in distilled water to give a stock concentration of $100 \mathrm{mg} \mathrm{l}^{-1}$ copper ions. Test solutions of $10,100,1000$, and $10000 \mu \mathrm{g} \mathrm{l}^{-1}$ nominal concentrations were obtained by diluting stock solutions in distilled water. Seawater (salinity 35\%) was prepared using artificial sea salts (Tropic Marin; Aquarientechnik).

Samples of the dogwhelk Nucella lapillus naturally infected with Parorchis acanthus were collected from the rocky shore of Stone Bay, Broadstairs, Kent, UK (National Grid Reference TR401683), and maintained in 81 Perspex tanks in a circulating, gravity-fed marine aquarium at $12^{\circ} \mathrm{C}$ and allowed to acclimatise for 2 mo.

Recently emerged cercariae (max. age $15 \mathrm{~min}$ ), in batches of 20 , were placed in $35 \mathrm{~mm}$ plastic petri dishes in $20 \mathrm{ml}$ of seawater containing the appropriate nominal toxic concentration of either 10, 100,1000, or $10000 \mu \mathrm{g} \mathrm{l}^{-1}$, or a control treatment of distilled water or a solvent control $\left(0.5 \mu \mathrm{g}\right.$ methanol $\left.\mathrm{ml}^{-1}\right) ; 6$ replicates of each test solution were used; these were then incubated at $20^{\circ} \mathrm{C}$ and the number of unencysting swimming cercariae was recorded at $3,6,9$, and $12 \mathrm{~h}$ intervals. Incubation continued for $48 \mathrm{~h}$ to ensure that a fully formed multi-layered cyst, normally found after $24 \mathrm{~h}$, had been properly established. At the end of this period the numbers of fully formed cyst were recorded. Data was analysed with the Unistat statistical software package, using the Lee-Desu comparison test for observations on swimming cercariae, and was arcsinetransformed and analysed using 1-way ANOVA for fully formed cysts.

The effects of toxic exposure of the snail host on subsequent Parorchis acanthus encystment were undertaken by randomly placing naturally infected Nucella lapillus in groups of 3 in glass beakers containing arti- ficial seawater in an incubator at $20^{\circ} \mathrm{C}$ under a $12 \mathrm{~h}$ light/dark regime and allowing them to acclimatise for $72 \mathrm{~h}$. Each group was then exposed to either a $10 \mu \mathrm{g} \mathrm{l}^{-1}$ nominal concentration of TBTO, copper, or irgarol or a control treatment of distilled water or a solvent control (methanol) in seawater. Solutions were renewed daily, and after $7 \mathrm{~d}$ each group was removed from the test solution, briefly rinsed in clean artificial seawater, and placed in dishes containing clean artificial seawater. Emergence of cercariae was induced by placing them under a strong cold light source (light intensity 1000 lux). For each group, recently emerged cercariae (max. age $15 \mathrm{~min}$ ), in batches of 20, were placed in $35 \mathrm{ml}$ plastic petri dishes in $20 \mathrm{ml}$ of clean artificial seawater; 6 replicates from each snail group were used and incubated at $20^{\circ} \mathrm{C}$. The number of swimming cercariae was recorded at $2,4,6,9$, and $12 \mathrm{~h}$ intervals. After $48 \mathrm{~h}$ incubation the number of fully formed cysts was counted and the data analysed as described for the previous experiment.

\section{RESULTS}

Under control conditions, encystment of Parorchis acanthus involved a rapid reduction in swimming cercariae during the first $6 \mathrm{~h}$ post-emergence, with most cercariae having started to encyst by $12 \mathrm{~h}$ post-emergence (Fig. 1). Although the difference in encystment speed between the 2 controls was significant (LeeDesu $\mathrm{p}=0.0020$ ) this was not carried over into the total encystment achieved after $48 \mathrm{~h}$ (1-way ANOVA, $F=$ $0.481, \mathrm{p}=0.5039$ ). Exposure to the nominal concentrations of toxic media caused variable effects on cercarial encystment. TBTO induced an inhibition of encystment compared to the solvent control at all concentrations (Lee-Desu $\mathrm{p}<0.0001$; Fig. 1a). After $6 \mathrm{~h}$ those cercariae exposed to $10000 \mathrm{\mu g} \mathrm{l}^{-1}$ TBTO began to swell and showed a reduction in activity. Death of cercariae that had failed to begin encystment by this time occurred soon after, all being dead by $12 \mathrm{~h}$. However, for copper and irgarol, significantly reduced encystment rates were demonstrated only in nominal concentrations of $1000 \mathrm{\mu g} \mathrm{l}^{-1}$ or higher compared to the solvent or distilled water controls respectively (Lee-Desu $\mathrm{p}<0.0001$ for copper; $\mathrm{p} \leq 0.0188$ for irgarol). All 3 toxic media induced significantly different responses between each other to cercarial encystment rate at all concentrations (Lee-Desu $\mathrm{p} \leq 0.0245$ ) except at $10000 \mu \mathrm{g} \mathrm{l}^{-1}$ where there was no difference between copper and irgarol exposures.

Total encystment after 48 h (Fig. 2) for all toxic solutions showed reduced encystment. At all nominal concentrations encystment was significantly reduced by TBTO (1-way ANOVA $F \geq 103.447, \mathrm{p}<0.0001$ ) and at 
nominal concentrations of $100 \mu \mathrm{g} \mathrm{l}^{-1}$ or higher for irgarol (1-way ANOVA $F \geq 11.307, \mathrm{p} \leq 0.0072$ ) compared to the solvent control. Copper significantly reduced encystment only at nominal concentrations of $100 \mathrm{\mu g} \mathrm{l}^{-1}$ or higher (1-way ANOVA $F \geq 16.151, \mathrm{p} \leq$

(a)

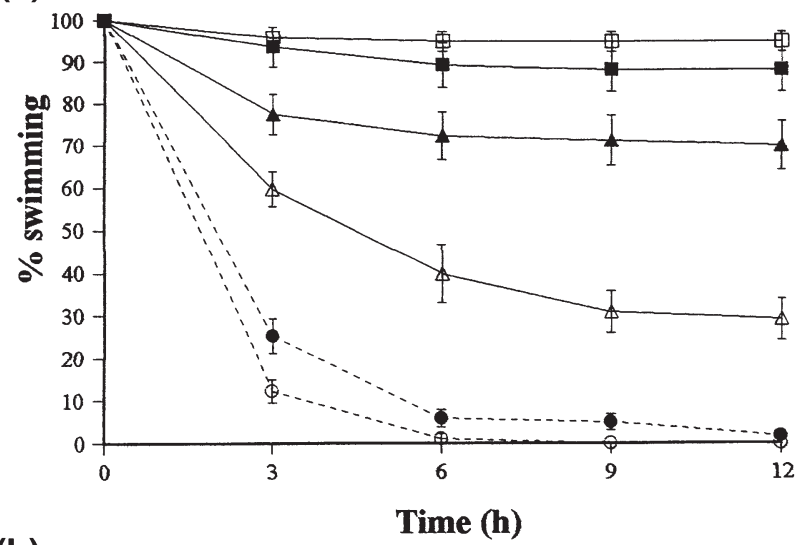

(b)

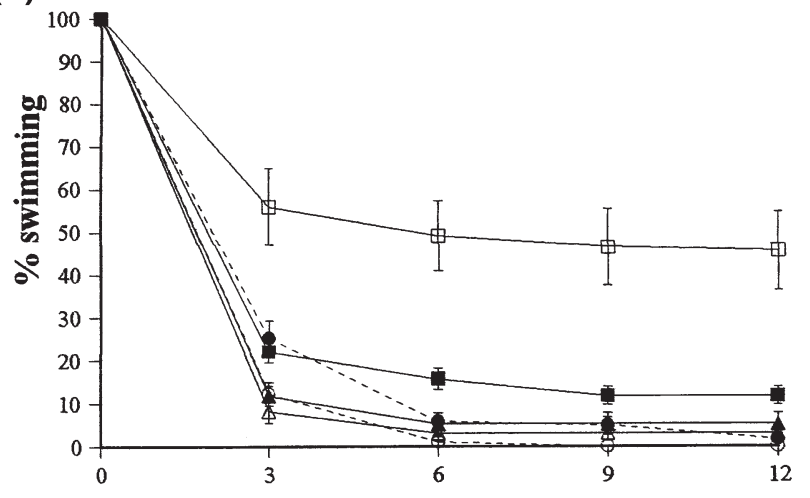

(c)

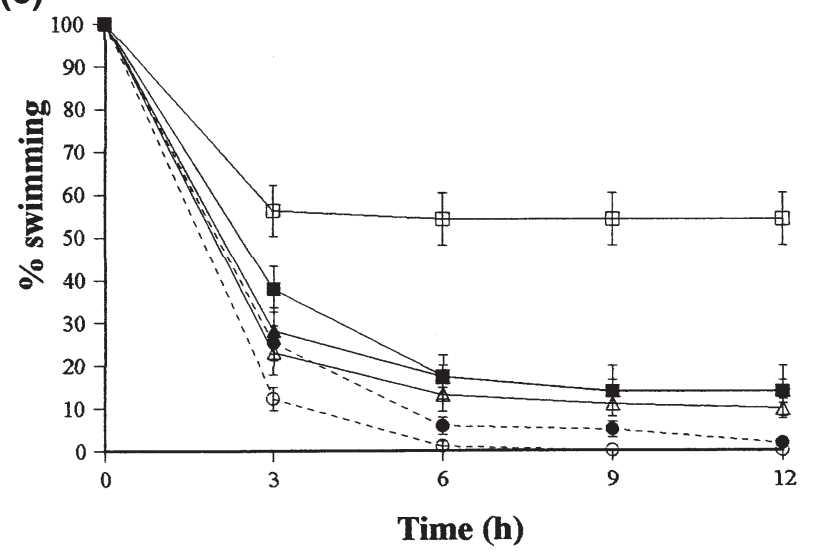

Fig. 1. Parorchis acanthus. Encystment rate (\% swimming) of cercariae exposed to (a) TBT, (b) irgarol, and (c) copper in nominal concentrations ranging from 10 to $10000 \mathrm{\mu g} \mathrm{l}^{-1}$. Error bars are standard errors. $(\bullet)$ Distilled water control; $(\circ)$ solvent

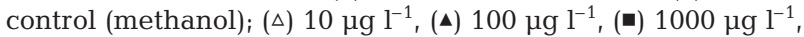
(ㅁ) $10000 \mathrm{\mu g} \mathrm{l}^{-1}$
0.0024). Several cercariae exposed to irgarol, that had failed to begin encystment after $48 \mathrm{~h}$, were still alive in the 1000 and $10000 \mathrm{~g} \mathrm{l}^{-1}$ nominal concentrations. At all nominal concentrations all test solutions demonstrated significantly different effects from each other on total encystment (1-way ANOVA $F \geq 25.060, \mathrm{p} \leq$ 0.0005), except copper and irgarol, for which differences were not significant other than at $10000 \mathrm{\mu g} \mathrm{l}^{-1}$ (1-way ANOVA $F \geq 5.918, \mathrm{p} \leq 0.0353$ ).

Exposure of the snail host Nucella lapillus to $10 \mu \mathrm{g} \mathrm{l}^{-1}$ nominal concentrations of the toxic biocides for $7 \mathrm{~d}$ had no effect on snail survival, but did have variable effects on the subsequent emerged cercarial encystment. Significant differences occurred between the 2 controls similar to the cercarial exposures for encystment speed (LeeDesu $\mathrm{p}=0.0126)$; however eventual total encystment results were non-significant (1-way ANOVA $F=3.089$, $\mathrm{p}=0.1093$ ). Exposure to irgarol caused a complete inhibition of cercarial emergence from the snail host, whilst exposure to TBTO and copper induced slower rates of emergence compared to the controls. However, the rate of encystment (Fig. 3a) showed no significant difference between biocide-exposed and control snails. Total encystment after $48 \mathrm{~h}$ (Fig. 3b) also showed no significant difference between control and biocide-exposed snails; however between TBTO and copper there was a significantly difference in total encystment induced (1-way ANOVA $F=12.837, \mathrm{p}=0.0059$ ).

\section{DISCUSSION}

The present study has demonstrated that several antifouling biocides may affect both the speed of encyst-

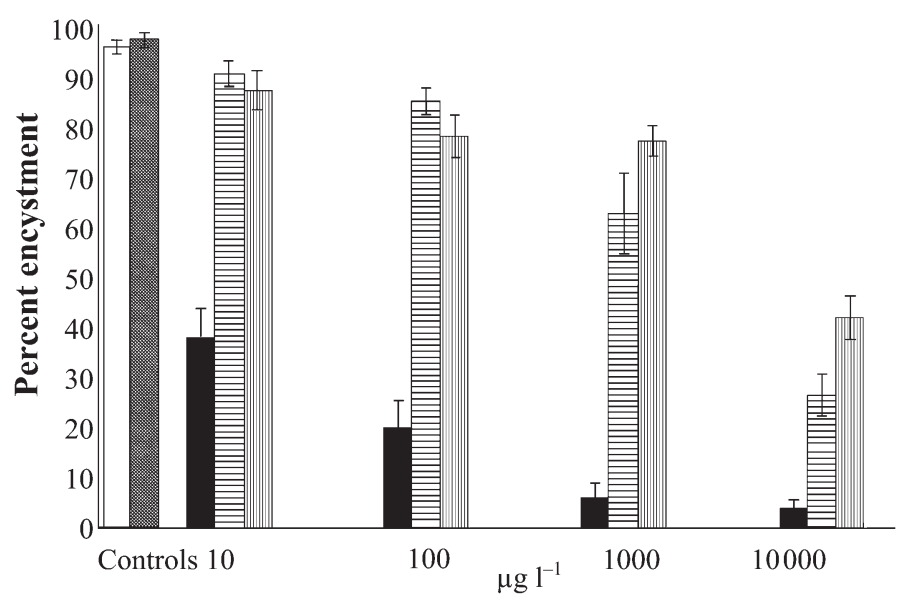

Fig. 2. Parorchis acanthus. Successful encystment in distilled water control ( $\square$ ), Solvent control (methanol) ( irgarol (三), copper (III) in nominal concentrations ranging from 10 to $10000 \mathrm{\mu g} \mathrm{l}^{-1}$. Error bars are standard errors 

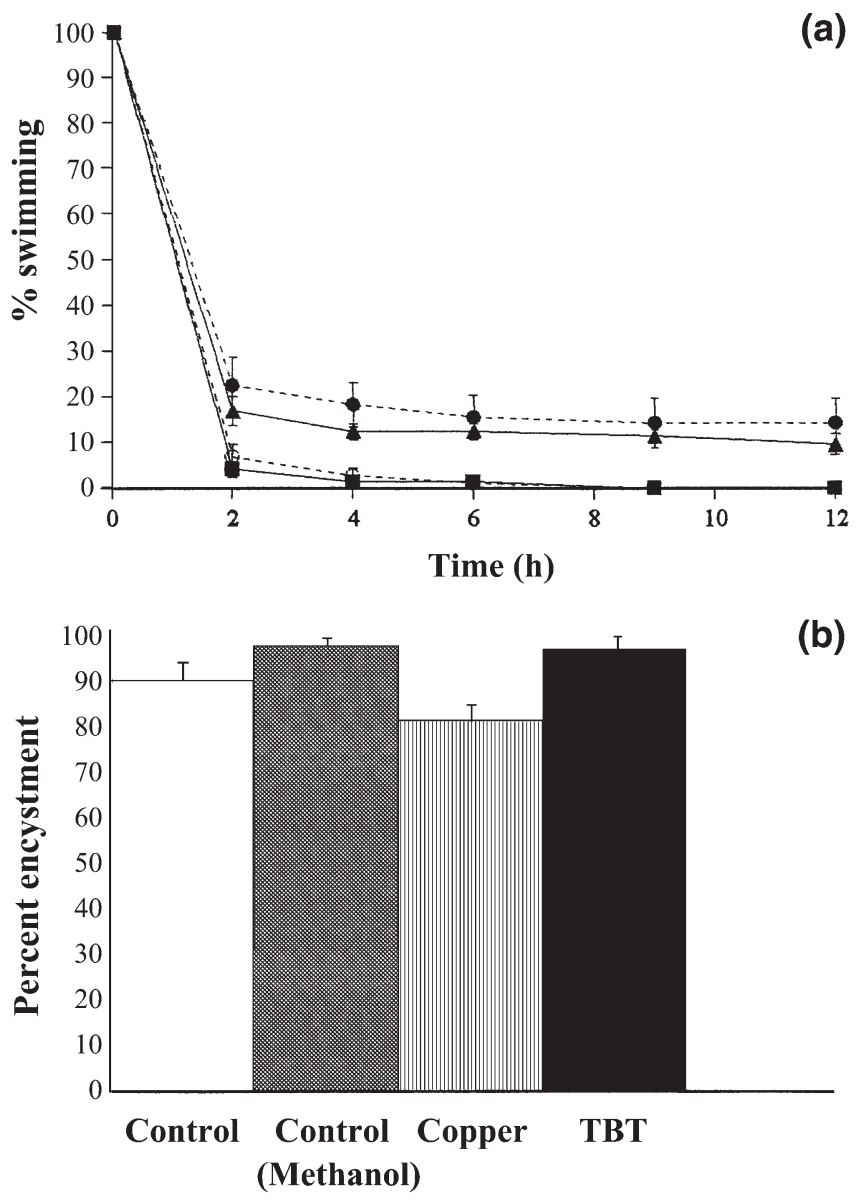

Fig. 3. Parorchis acanthus. Encystment rate (\% swimming) of cercariae from snail hosts following exposure to $10 \mathrm{\mu g}^{-1}$ nominal concentrations of anti-fouling biocides for $7 \mathrm{~d}$ (no data for irgarol are presented due to its complete suppression of cercarial emergence in the snail host). (a) Encystment rate of cercariae $(\bullet)$ distilled water control; $(\circ)$ solvent control

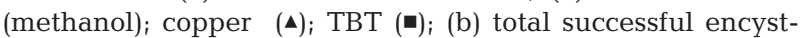
ment. Error bars are standard errors

ment of Parorchis acanthus and the ability to form a complete multi-layered cyst. Previous studies have found that changing environmental parameters may alter $P$. acanthus encystment rates. Decreasing salinity (Stunkard \& Shaw 1932), increasing salinity (Rees 1937) and increasing temperature (Williams 1969) accelerate the rate of encystment. Laurie (1974), however, found that exposure to the enzyme casein hydroysate failed to alter encystment rates. Changes in the speed of encystment were considered a response to 'unfavourable conditions' and did not appear to have an adverse effect on the cercariae themselves. In the present study, significant changes in encystment rate between the 2 controls occurred, the solvent control inducing an increased encystment rate. However, as the concentration of methanol used in the solvent control $(0.5 \mu \mathrm{g}$ methanol $\mathrm{ml}^{-1}$ ) is considered non-toxic (Nishiuchi \& Hashimoto 1967), and induced an increased encystment rate compared to the slowed rate of toxin-exposed cercariae that led to an eventual total encystment which was not significantly different from the distilled water control, these differences may also reflect a behavioural response to 'unfavourable conditions' by the parasite, and are probably not a result of toxic exposure.

Toxic substances have not previously been investigated against encystment rates of digeneans. In the present study encystment was slowed by the addition of all nominal concentrations of TBTO, and concentrations of $1000 \mu \mathrm{g} \mathrm{l}^{-1}$ or higher of copper and irgarol. Both TBTO and irgarol are rapidly absorbed by plastic ware, such as the petri dishes in this study, and the toxicity demonstrated by these substances probably occurred within the first hour of exposure. Graczyk \& Shiff (1994) noted that when cercariae of the freshwater species Notocotylus attenuatus were mechanically stimulated to prolong their swimming period prior to encystment, they had a significantly reduced longterm viability within the cyst. It is conceivable that the prolonged swimming exhibited by Parorchis acanthus exposed to anti-fouling biocides in the present study may also have reduced cyst viability even in those individuals successfully forming a cyst. Nevertheless, the present study has demonstrated that several cercariae failed to achieve a full multi-layered protective cyst even at concentrations which had failed to induce changes in the encystment rate $\left(100 \mu \mathrm{g} \mathrm{l}^{-1}\right.$ copper and irgarol), suggesting that the encysting cercariae were vulnerable to the toxic action of the biocides. Reduced encystment in $P$. acanthus has previously been reported under exposure to cadmium and zinc (Morley et al. 2001), who suggested that inhibition of cyst formation by toxic metals was the same as that proposed by Evans (1982) for copper and zinc toxicity to N. attenuatus, whereby metals inhibited the complete extrusion and unrolling of the 'keratin-like' granules from the cystogeneous glands necessary for forming the inner cyst wall. It is possible that a similar mode of inhibition may have occurred in the present study.

The toxic action of tributyltin has previously been investigated against the cercariae of Schistosoma mansoni. Ritchie et al. (1974) found that cercariae were rapidly inactivated and infectivity suppressed after a 5 min exposure to $100 \mu \mathrm{g} \mathrm{l}^{-1}$ TBTO. Viyanant et al. (1982) found that although cercarial survival was greater than $90 \%$ after a $1 \mathrm{~h}$ exposure to concentrations between 6 and $10 \mu \mathrm{g} \mathrm{l}^{-1}$ tributyltin fluoride, infectivity was totally suppressed. Reduced cercarial activity after exposure to tributyltin was also found in the present study. However, as Parorchis acanthus does not actively penetrate its target host, the influence of TBTO on transmission is debatable. Morley et al. 
(2001) found that in vitro excystment of $P$. acanthus could only be affected by acutely high concentrations of cadmium and zinc, yet both of these toxicants have been found to reduce the activity of Diplostomum spathaceum cercariae significantly at concentrations as low as $0.1 \mu \mathrm{g} \mathrm{l}^{-1}$ (N. J. Morley unpubl. obs.). Indeed, Cross et al. (2001) reported that several heavy metals at concentrations of $1 \mathrm{mg} \mathrm{l}^{-1}$ or higher reduced the horizontal swimming speed of the marine cercaria Cryptocotyle lingua.

Exposure of the host snail Nucella lapillus for $7 \mathrm{~d}$ to $10 \mathrm{\mu g} \mathrm{l}^{-1}$ of the biocides had little influence on subsequent encystment of Parorchis acanthus for either TBTO or copper. This may be associated with the pathological effect digeneans have on the digestive gland of their snail host. This organ is the main accumulator of a variety of metals, but it is also subject to extensive damage caused by feeding digeneans such as $P$. acanthus (Rees 1966). Parasitized marine snails have been found to have significantly lower accumulated levels of metals than uninfected ones (Evans et al. 2001). This is considered to be a product of parasiteinduced pathology reducing the storage volume and holding capacity of the digestive gland for metals (Evans et al. 2001), which may consequently reduce the likelihood of toxic build-up of metals in tissues adjacent to the parasite redia. Nevertheless, Cross et al. (2001) reported that Cryptocotyle lingua cercariae that emerged from Littorina littorea collected from a metalpolluted site had significantly reduced longevity and horizontal swimming speed compared to those from hosts collected from an unpolluted site. Such changes in the functional biology of cercariae may be due to the long-term, chronic pollution to which host snails have been exposed, and may induce comparable changes for TBTO- and copper-exposed N. lappilus/P. acanthus under similar natural conditions. In contrast, the present study has shown that irgarol completely suppresses cercarial emergence. Suppression of cercarial emergence has previously been reported for the freshwater snail Biomphalaria glabrata infected with Schistosoma mansoni when the former was exposed to the antihelmitic drug praziquantel (Riley \& Chappell 1990). Irgarol has been demonstrated to induce significantly slower growth and development in a number of aquatic invertebrates (Hall et al. 1999). Intra-molluscan stages of $P$. acanthus may be subjected to similar effects which curtail cercarial development and mass production.

In conclusion, the present study has demonstrated that the cercarial stage of Parorchis acanthus can be significantly affected by the presence of acute concentrations of anti-fouling biocides. Although the concentrations used in the present study are higher than those normally encountered in polluted environments, nevertheless the effects on cyst formation demonstrated by the accelerated toxicity testing of this study may indicate increased susceptibility of the free-living parasite stages to anti-fouling biocides. If the protective effects of a fully formed cyst are undermined in chronically polluted sites, the long-term viability of the metacercariae and its subsequent development to gravid adults in the definitive bird host are at risk. This may have significant implications for its survival in natural systems subject to boating activity.

Acknowledgements. We would like to thank The Croucher Foundation, Hong Kong, for providing the funding and a postdoctoral research fellowship to K.M.Y.L., and Ciba Speciality Chemicals, UK, for kindly providing a sample of Irgarol 1051.

\section{LITERATURE CITED}

Bryan GW, Gibbs PE, Burt GR, Hummerstone LG (1986) The decline of the gastropod Nucella lapillus around southwest England: evidence for the effects of tributyltin from anti-fouling paints. J Mar Biol Assoc UK 66:611-640

Cross MA, Irwin SWB, Fitzpatrick SM (2001) Effects of heavy metal pollution on swimming and longevity in cercariae of Cryptocotyle lingua (Digenea: Heterophyidae). Parasitology 123:499-507

Evans DW, Irwin SWB, Fitzpatrick S (2001) The effect of digenean (Platyhelminthes) infections on heavy metal concentrations in Littorina littorea. J Mar Biol Assoc UK 81: $349-350$

Evans LV (1981) Marine algae fouling: a review, with particular reference to ship-fouling. Bot Mar 24:167-171

Evans NA (1982) Effects of copper and zinc on the life cycle of Notocotylus attenuatus (Digenea: Notocotylidae). Int J Parasitol 12:363-369

Evans SM, Kerrigan E, Palmer N (2000) Causes of imposex in the dogwhelk Nucella lapillus (L.) and its use as a biological indicator of tributyltin contamination. Mar Pollut Bull 40:212-219

Graczyk TK, Shiff CJ (1994) Viability of Notocotylus attenuatus (Trematoda: Notocotylidae) metacercariae under adverse conditions. J Wildl Dis 30:46-50

Hall LW Jr, Giddings JM, Solomon KR, Balcomb R (1999) An ecological risk assessment for the use of Irgarol 1051 as an algaecide for antifoulant paints. Crit Rev Toxicol 29: $367-437$

Laurie JS (1974) Himasthla quissetensis: induced in vitro encystment of cercariae and ultrastructure of the cyst. Exp Parasitol 35:350-362

Morley NJ, Crane M, Lewis JW (2001) Toxicity of cadmium and zinc to encystment and in vitro excystment of Parorchis acanthus (Digenea: Philophthalmidae). Parasitology 122:75-79

Nishiuchi Y, Hashimoto Y (1967) Toxicity of pesticide ingredients to some freshwater organisms. Sci Pest Control 32: $5-11$

Rees G (1937) The anatomy and encystment of Cercaria purpurae Lebour, 1911. Proc Zool Soc Lond 107:65-73

Rees G (1966) Light and electron microscope studies of the redia of Parorchis acanthus Nicoll. Parasitology 56: $589-602$

Riley EM, Chappell LH (1990) Praziquantel treatment of Biomphalaria glabrata infected with Schistosoma mansoniinfluences on snail fecundity. Parasitology 101:211-217 
Ritchie LS, Lorez VA, Cora JM (1974) Prolonged application of an organotin against Biomphalaria glabrata and schistosomiasis control. In: Cheng TC (ed) Molluscicides in schistosomiasis control. Academic Press, New York, p 77-88

Stunkard HW, Shaw CR (1932) The effects of dilution of sea water on the activity and longevity of certain marine cercariae, with descriptions of two new species. Biol Bull 61:242-271

Editorial responsibility: Thomas Braunbeck, Heidelberg, Germany
Viyanant V, Thirachantra S, Sornmani S (1982) The effect of controlled release copper sulphate and tributyltin fluoride on the mortality and infectivity of Schistosoma mansoni cercariae. J Helminthol 56:85-92

Williams MO (1969) Cercaria Parorchis acanthi in marine molluscs from Sierra Leone with notes on survival of the cercaria and development of the metacercaria in a definitive host. Rev Zool Bot Afr 79:265-272

Submitted: February 20, 2002; Accepted: August 8, 2002 Proofs received from author(s): March 3, 2003 